\title{
DAMAGE LIMIT STATES FOR CONFINED MASONRY WALLS BASED ON EXPERIMENTAL TEST
}

\author{
Carlos ZAVALA ${ }^{1,2}$, Miguel DIAZ ${ }^{1,2^{*}}$, Erika FLORES ${ }^{1,2}$, Lourdes CARDENAS ${ }^{2}$ \\ ${ }^{1}$ Civil Engineering Faculty, National University of Engineering, Lima, Peru. \\ 2 Japan-Peru Center for Earthquake Engineering Research and Disaster Mitigation, Lima, Peru.
}

Received: 28/07/2019 Accepted: 12/08/2019

\begin{abstract}
Non engineering dwellings represents $83 \%$ of the stock of housing in emerging areas of Lima city. These dwellings are build with non-appropriated masonry bricks with walls that limits don't meet the displacement control of the earthquake design standards NTE-030 and NTE-070. Considering the database of structural test of 33 years of experimental studies of the Structural Laboratory of CISMID, typical behavior curves are studied in order to propose damage limit state for masonry walls: build with industrial bricks, build with handmade bricks and build with horizontal hollow tubular bricks. Also, results of full-scale test on masonry house performed in the laboratory are studied. Ranges of inelastic development limit states of walls are proposed from the test results of full-scale test of the three types of masonry. Big difference in the capacity of walls with tubular bricks in comparison with the others types are found. Also limit drift values threshold are propose to be use in the analytical modelling of wall structures with handmade or tubular bricks. These proposal limits are smaller than the limit of NTE-030 standard.
\end{abstract}

Keywords: Masonry, non-engineering wall, tubular hollow brick, handmade brick, limit state ranges.

\section{INTRODUCTION}

The evaluation of a masonry building demands the generation of mathematical models with simple or complex idealization in order to obtain the performance of the building for the design earthquake. Some tools has been developed in order to estimate the damage limit states for different structural systems such framed, concrete walls and also masonry walls. However, in the last structural type, the limit states are construction quality dependence and are not well known. In this paper a proposal of limit states for confined masonry walls based on experimental test is presented, consider the data of 30 years of laboratory test performed in the structural laboratory of CISMID, with emphasis in the study of non-engineering constructions which is a representative for dwellings in Lima and surrounding urban areas.

\section{NON-ENGINEERING BUILDINGS}

The non-engineering buildings in Peru represents $83 \%$ of the stock of buildings in urban areas, according with seismic risk studies conducted by CISMID since 2010, by order of the Ministry of Housing, Construction and Sanitation (MVCS), the National Center for the Estimation, Prevention and Reduction of Disaster Risk
(CENEPRED) and Ministry of Economy and Finance (MEF) [6]. This kind of building is characterized by nonconfine elements on wall boundaries and non-collar beam in their story level. In addition, there are buildings who presents confinement walls but use as material horizontal hollow bricks which are fragile in resistance of gravity and seismic loads. The reason, the low cost of these bricks.

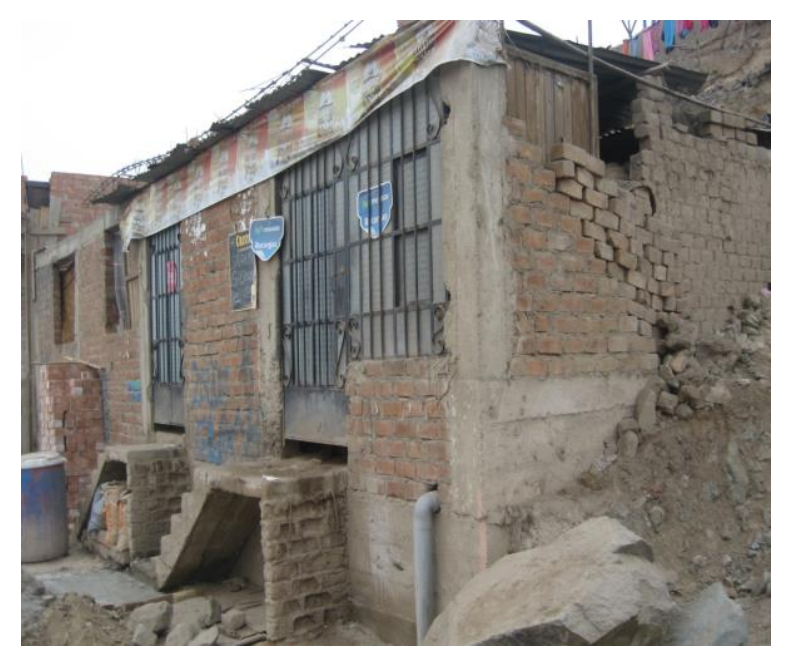

Figure 1. Non engineering confined masonry dwelling.

\footnotetext{
* Corresponding author:

czavala@uni.edu.pe
} 
Therefore, the dwelling shows in Figure 1, represents housing in emerging urban areas on Lima city, usually on hill site. Another example of masonry dwelling are the houses which are located over non competent soils, such Lomo de Corvina area in southern Lima, show in Figure 2.

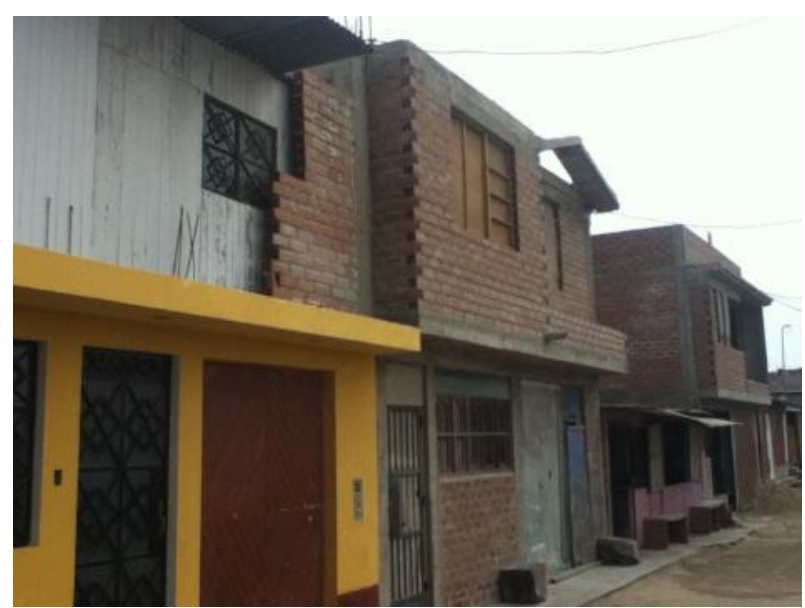

Figure 2. Tubular blocks on masonry dwelling

One of the districts with high population in southern Lima is Villa El Salvador, which is a zone limiting with the pacific ocean, Here the cliffs areas were invaded on 1970, and named Corvine Loin (Lomo de Corvina in Spanish), where people build the houses in artisanal wave with non-control. Therefore, non-engineering dwelling represents this area. Figure 3, shows the results of an analysis of vulnerability [15], presenting $29 \%$ with high vulnerability, $10 \%$ with middle vulnerability and $60 \%$ with low vulnerability.

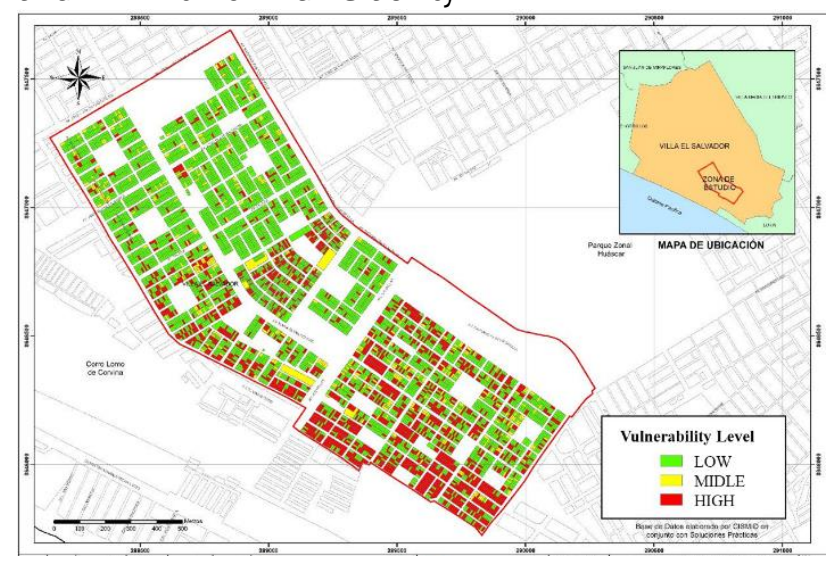

Figure 3. Vulnerability map - Lomo de Corvina [15].

Similar scenarios has been studied for Lima city [16], however it is necessary to consider limit states for the types of masonry used specially in non-engineering houses. Therefore, these limit states for the different kinds of masonry walls test proposed by CISMID database of masonry walls test collected in 30 years [1], are presented using three kinds of masonry units: industrial solid block, horizontal hollow bricks and handmade solid bricks (see Fig. 1), the first one have an DOI: https://doi.org/10.21754/tecnia.v29i2.715 appropriated resistance and the last two have lower resistant capacity and represents lower limit values from the recommended for bearing walls by NTE-070 Peruvian standard.

\section{MASONRY HOUSE LIMIT STATES FROM FULL SCALE TEST}

The Structural Laboratory of CISMID-FIC-UNI has a 30 years database of full-scale masonry wall tests performed under different axial conditions, materials and confined elements. Also, test considering real house was developed in the laboratory [17]. Using the results of this test a first proposal from a real house test was presented.

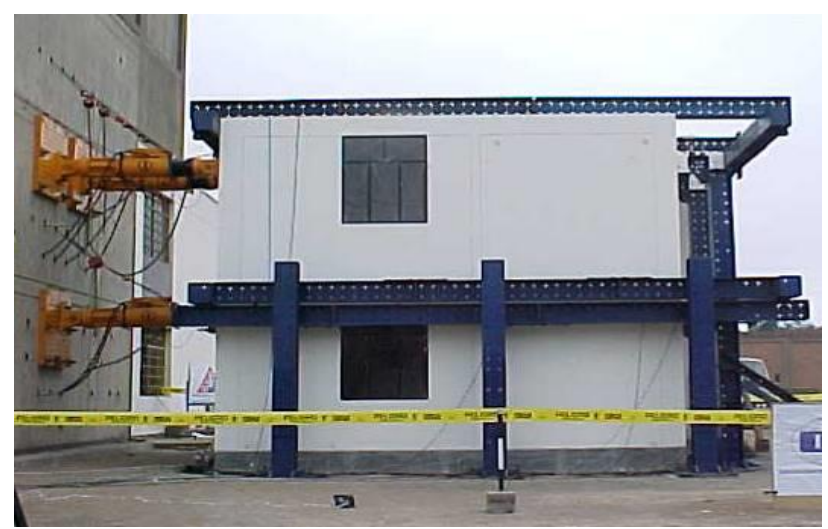

Figure 4. Full-scale test of masonry house [17]

Initial cracking of the specimen starts for a drift of $1 / 1600$ with cracks of $0.05 \sim 0.10 \mathrm{~mm}$. and become notorious after $1 / 800$ when cracks of $1.2 \mathrm{~mm}$. appeared. A maximum base shear $147.86 \mathrm{t}$. was the failure load of the specimen under a drift of $1 / 65$ with cracks from side between 5 10 $\mathrm{mm}$. in thickness.

In order to propose damage limit states from this real house experiment [17], the behavior curve is linked with the damage in each stage of the experiment. Using the same view presented in Figure 4, each of the stage mentioned in the above paragraph is show in the following figures.

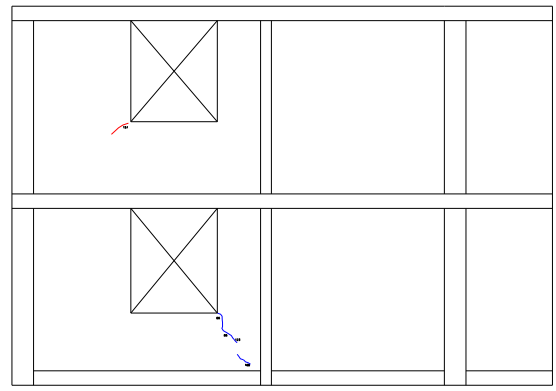

Figure 5: Damage state at 1/1600

Journal TECNIA Vol.29 N² July-December 2019 


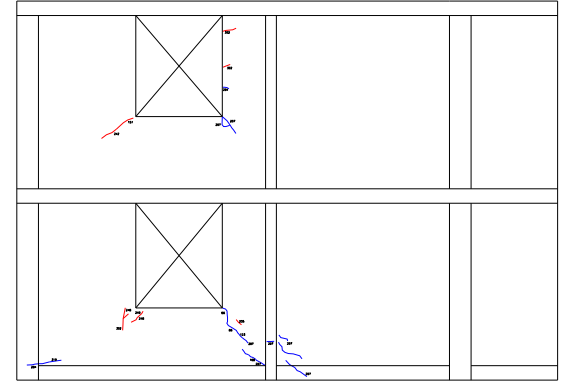

Figure 6: Damage state at 1/800

The windows without join isolation is one of the more likely places where cracks start during earthquakes, therefore, during the experiment the first cracks appear around windows openings when drift reach $1 / 1600$, with crack's thickness less than $0.5 \mathrm{~mm}$. End of linear behavior is generated when cracks opening is over 1.0 $\mathrm{mm}$ and appears at on confined elements and cracks from windows reach these elements at drift of $1 / 800$ and cracks appears on non-opening center wall. Here operation limit threshold is set on a drift range form zero to $1 / 1000$ because from $1 / 1000$ to $1 / 800$ the reinforce bars on the vertical confine elements yields. In this range propagation of cracks on masonry walls and also cracking and confine elements shows the starting of deterioration on the structure. Therefore, this define the immediate operation state for the structure.

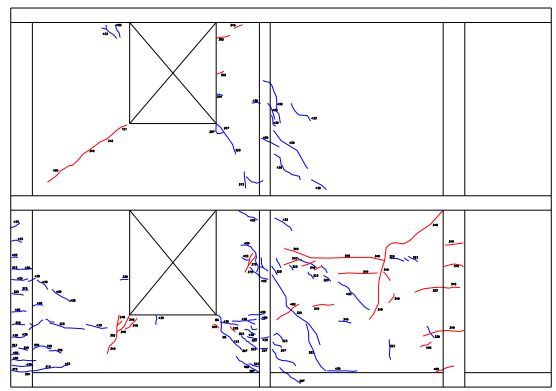

Figure 7: Damage state at 1/400

As mentioned before, non linear behavior and deterioration on the masonry walls started to be notorious in the drift range of $1 / 800$ to $1 / 400$, with cracks of $2 \mathrm{~mm}$. but less than $4 \mathrm{~mm}$, with a damage state as shown in Figure 7, here cracks on confined elements start to be notorious. Diagonal cracks started at drift $1 / 330$ generating a state with diagonal cracks in both floors and both sides of the walls as is presented on Figure 8

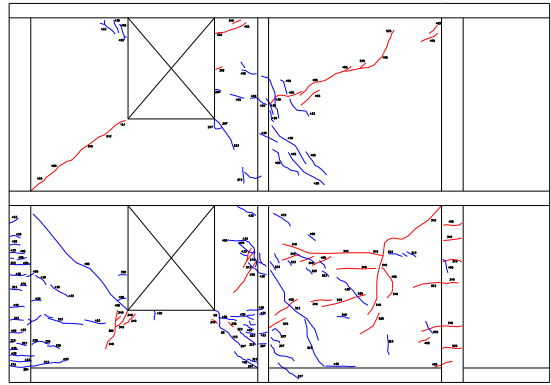

Figure 8: Damage state at 1/200

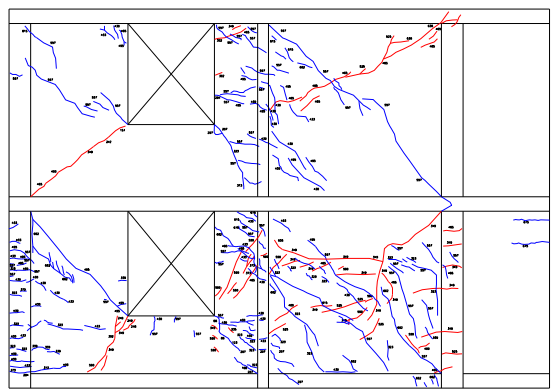

Figure 9: Damage state at 1/100

When drift of $1 / 200$ is reached, glass on windows start to broken. In a real house it will be a risk for the occupants and by a drift of 1/150 is not save to be inside the house. Deterioration on confined elements with cracks on walls bigger than $6 \mathrm{~mm}$. and also cracks of 2 $\mathrm{mm}$. on confined elements, as is presented for $1 / 100$ drift. Also at this stage windows and doors can not close due to the movement.

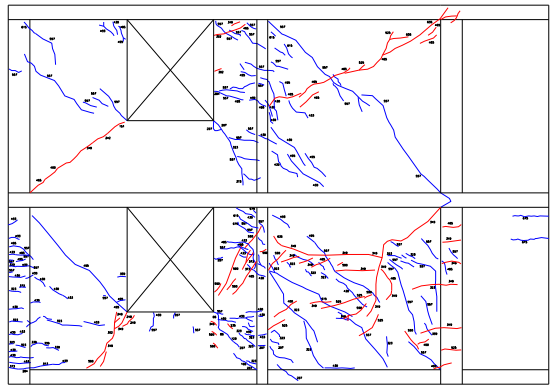

Figure 10: Damage state at 1/65

Finally, ultimate base shear is reach with $1 / 65$ drift with generalize opening cracks of $10 \mathrm{~mm}$. with strong deterioration in walls and confined elements, with doors and windows impossible to use. 

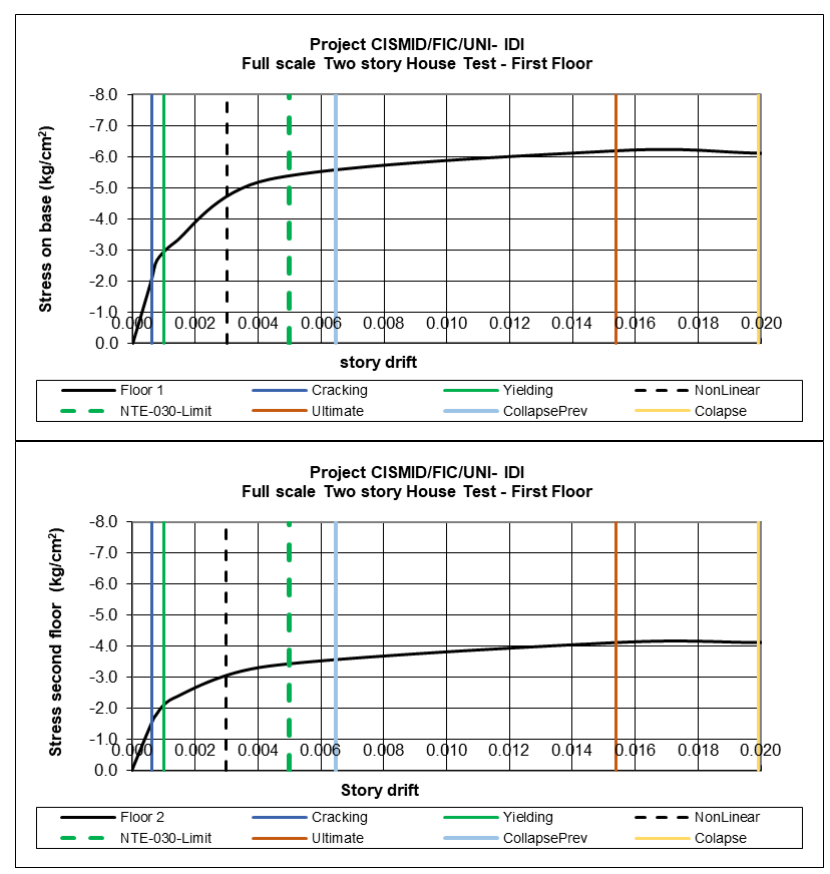

Figure 11: Damage states on behavior curve

Considering the results of the behavior curve [17] for the first and second floor express in terms of shear stress for each floor and drift values, limit state values states are presented on Figure 11. Here the behavior presented previously on Figures 5 to 10, where the damage has been linked with the curves. Also limit values are shown in Table 1, where cracking drift, yielding drift, non linear representative drift, collapse prevention drift, ultimate capacity drift and collapse drift are presented. Here values are presented numerically and in fraction.

Table 1. Drift values

\begin{tabular}{llcc}
\hline Cracking & Yielding & NonLinear & NTE-030 \\
\hline 0.0006 & 0.0010 & 0.0030 & 0.0050 \\
$1 / 1600$ & $1 / 1000$ & $1 / 333$ & $1 / 200$ \\
NTE-030 & Collapse P & Ultimate & Collapse \\
0.0050 & 0.0065 & 0.0154 & 0.0200 \\
$1 / 200$ & $1 / 155$ & $1 / 65$ & $1 / 50$ \\
\hline
\end{tabular}

In order to define state ranges measure from the inelastic zone, in the range between the yielding and the collapse values. Table 2 presents the limit state range for collapse $(C)$ between the maximum and collapse, the collapse prevention (CP) between maximum and collapse prevention value, life safety range (LS) between collapse prevention value and considerable deterioration non-linear value, immediate occupation (IO) range between non-linear value and yielding. The house is complete operated for drift less than $1 / 1600$ where house is considered to be in elastic range.

Table 2. Limit State Ranges on inelastic zone

\begin{tabular}{cr}
\hline Limit State & Range \% \\
\hline C & $24.3 \%$ \\
CP & $46.9 \%$ \\
LS & $18.2 \%$ \\
IO & $10.5 \%$ \\
O & -- \\
\hline
\end{tabular}

\section{WALLS LIMIT STATES FROM EXPERIMENTAL TEST}

As was mentioned at item 2, Peruvian housing are build with different kinds of masonry walls, where near $82 \%$ of the housing buildings classify as non-engineering structures. Under this scenario during and earthquake the behavior of this walls will not be as retrofit limit from Masonry Standards NTE-E-070 and Earthquake design standard NTE-E-030 due to use of non-regulated masonry. Using data results form [1], [2],[3], $[8],[10],[13]$ and $[14]$, it is possible to consider the linearization of behavior curves from data base results and present 3 curves that represent the behavior of walls with industrial solid brick, walls with handmade brick, and walls with horizontal hollow brick also name tubular hollow bricks, presented in Figure 12.

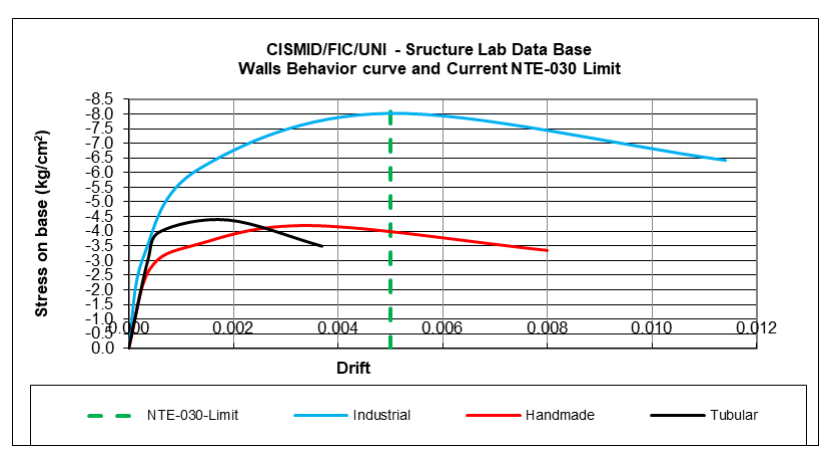

Figure 12: Behavior curve of three kinds of masonry

In the above figure it is possible to see the threshold limit value from the earthquake design standards NTEE-030 for masonry buildings. This value is a threshold that divide the state of reparation of the building with the state of collapse or collapse prevention of the building. In the figure is possible to see that only the wall build with industrial solid brick meets the standards. Therefore, walls build with handmade brick and tubular brick have should be evaluate with different thresholds. 


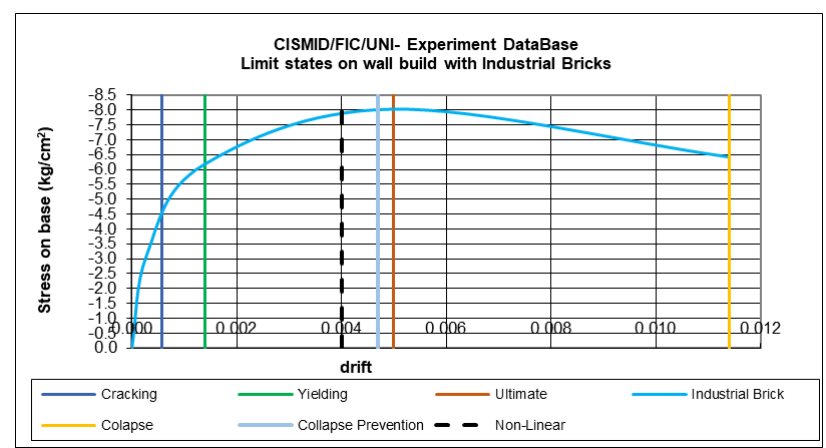

Figure 13: Damage states wall with industrial bricks

On Figure 13 the drift with stress behavior curve for wall build with industrial bricks is presented. In the figure limit values are presented, where each of the drift limit state are shown in Table 3. As was mentioned before, threshold of NTE-030 standards feet the curve just before the collapse prevention drift.

Table 3. Drift values for wall with industrial bricks

\begin{tabular}{llcc}
\hline Cracking & Yielding & Nonlinear & NTE-030 \\
\hline 0.0006 & 0.0014 & 0.0040 & 0.0050 \\
$1 / 1754$ & $1 / 714$ & $1 / 250$ & $1 / 200$ \\
NTE-030 & Collapse P & Ultimate & Collapse \\
0.0050 & 0.0047 & 0.0114 & 0.0200 \\
$1 / 200$ & $1 / 212$ & $1 / 88$ & $1 / 50$ \\
\hline
\end{tabular}

Limit state ranges are presented in Table 4, measure from the inelastic zone, in the range between the yielding and the collapse values. Here the ranges are different from the ones presented on Table 2 for the full-scale house experiment, this can be attributed to the number of walls, the action of perpendicular walls, the interaction with the slabs, and other parameters involve in the experiment.

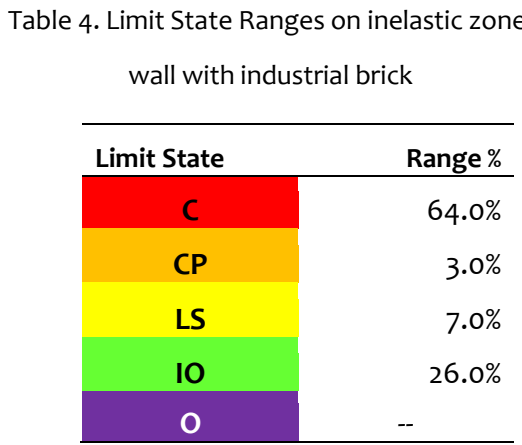

In comparison with the other kinds of walls (Figure 12), capacity is higher than others and values meets the standards and can be consider the ideal wall. However more of the housing in the country are build with the other kinds of walls.

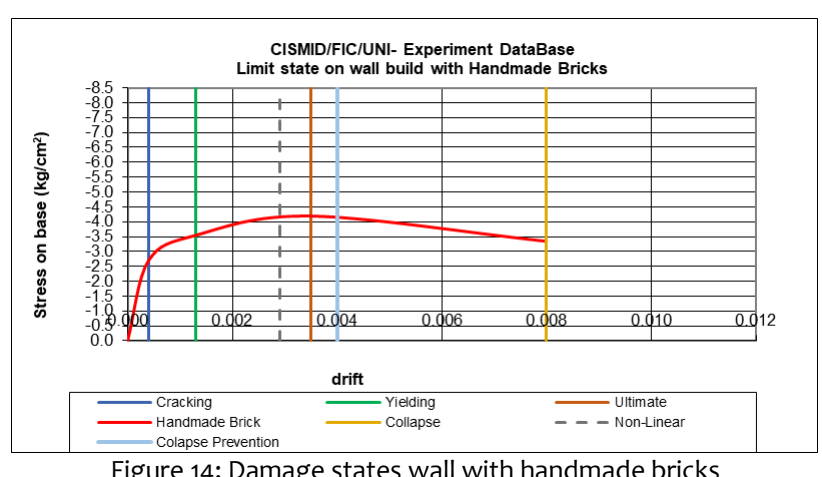

Figure 14: Damage states wall with handmade bricks

The wall with handmade bricks is likely used in emerging areas. These bricks are usually produced in small factories in artisanal way and sometimes are not well cook in artisanal oven. Therefore, capacity is presented in Figure 14 where limits are presented. Here the capacity is quite lower than industrial brick wall and standard threshold is not valid as presented in Figure 12. New threshold is proposed on this paper for this type of wall with a value of $1 / 300$, show on Table 5 , with a value between the nonlinear behavior limit and the collapse prevention limit

Table 5. Drift values for wall with handmade bricks

\begin{tabular}{llcc}
\hline Cracking & Yielding & Nonlinear & Threshold \\
\hline 0.0004 & 0.0013 & 0.0029 & 0.0033 \\
$1 / 2500$ & $1 / 769$ & $1 / 350$ & $1 / 300$ \\
Threshold & Collapse P & Ultimate & Collapse \\
0.0033 & 0.0040 & 0.0035 & 0.0080 \\
$1 / 300$ & $1 / 250$ & $1 / 286$ & $1 / 125$ \\
\hline
\end{tabular}

Table 6. State Ranges on inelastic zone wall with handmade brick

\begin{tabular}{cr}
\hline Limit State & Range \% \\
\hline C & $60.0 \%$ \\
CP & $7.0 \%$ \\
LS & $9.0 \%$ \\
IO & $24.0 \%$ \\
O & - \\
\hline
\end{tabular}

State limit ranges for wall build with handmade bricks are presented on Table 6, where it is possible to read that immediate operation (IO) range is a little bit lower than (IO) on wall with build with industrial bricks. 


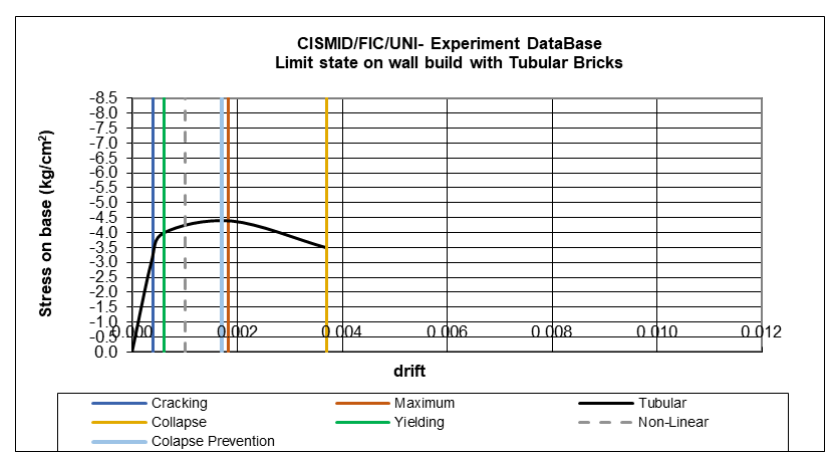

Figure 15: Damage states wall with tubular bricks

On Figure 15 behavior curve for wall build with tubular bricks is presented. As was shown in Figure 12, this type of wall is the lower in capacity due to the nature of its bricks with horizontal hollow. For this wall type, threshold of $1 / 590$ is proposed with a value near the collapse prevention value.

Table 7. Drift values for wall with tubular bricks

\begin{tabular}{lllc}
\hline Cracking & Yielding & Nonlinear & Threshold \\
\hline 0.0005 & 0.0007 & 0.0010 & 0.0017 \\
$1 / 2150$ & $1 / 1500$ & $1 / 1000$ & $1 / 590$ \\
Threshold & Collapse P & Ultimate & Collapse \\
0.0017 & 0.0016 & 0.0018 & 0.0037 \\
$1 / 590$ & $1 / 588$ & $1 / 550$ & $1 / 270$ \\
\hline
\end{tabular}

Table 8. State Ranges on inelastic zone

wall with tubular brick

\begin{tabular}{cr}
\hline Limit State & Range $\%$ \\
\hline C & $61.0 \%$ \\
CP & $7.0 \%$ \\
LS & $19.0 \%$ \\
IO & $13.0 \%$ \\
O & - \\
\hline
\end{tabular}

State limit ranges for wall build with tubular bricks are presented on Table 8, where it is possible to read that immediate operation (IO) range is lower, almost half, than (IO) on wall with build with industrial bricks. It means after cracking capacity is smaller than the other two types of masonry.

Table 9. State Ranges on inelastic zone for Peruvian Masonry walls

\begin{tabular}{crrr}
\hline State & Industrial & Handmade & Tubular \\
\hline C & $64.0 \%$ & $59.7 \%$ & $60.6 \%$ \\
CP & $3.0 \%$ & $7.5 \%$ & $7.1 \%$ \\
LS & $7.0 \%$ & $9.0 \%$ & $19.4 \%$ \\
IO & $26.0 \%$ & $23.9 \%$ & $12.9 \%$ \\
O & $0.0 \%$ & $0.0 \%$ & $0.0 \%$ \\
\hline
\end{tabular}

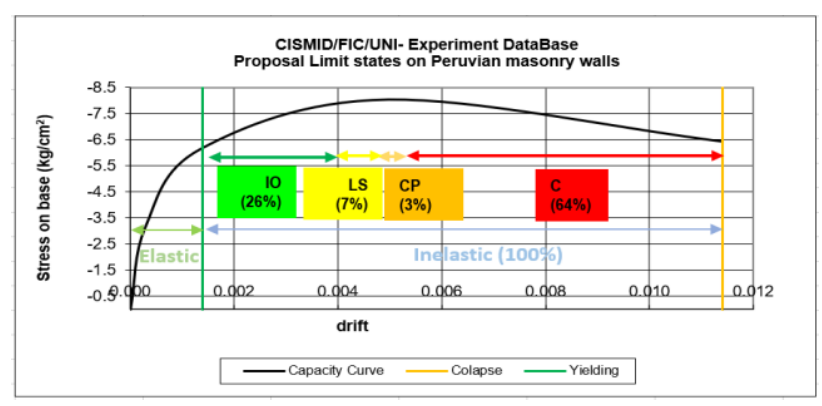

Figure 16: Damage states range example

To resume the damage state ranges and the use for earthquake analysis modeling, table 9 summarize the ranges for all the presented wall types. Figure 16 shows the use of this range for a capacity curve dividing the inelastic range in sub-ranges with each of the damage states and its applicability for modeling such push over analysis in order to find the performance of the structure for a demand spectrum with a target damping.

\section{CONCLUSIONS}

Results of [6] and [15] shows the real situation of the masonry dwellings in Lima city. The non-engineering buildings are not include on the insurance portfolio, but during and earthquake the amount of damage will over $29 \%$ of the stocks. The transfer and the promotion of the risk areas in Lima is a pending task for the local governments.

Full scale house build with handmade bricks show a representative curve and damage ranges that presents ultimate capacity reserve (from yielding to ultimate) more than twice of standard NTE-030 threshold (0.005) giving confidence in the use of the standard where this limit is prior to the collapse prevention range. The construction of this sample specimen was executed with artisanal bricks but the standards was followed during the construction process.

By the use of database of the structural laboratory of CISMID, the behavior curves for three types of masonry walls were presented, identifying the damage ranges (Table 9, Figure 16) and limit values (Table 3, Table 5 and Table 7). It is possible to read similar tendency in range of collapse (C) and collapse prevention (CP) and have different values on the other ranges. Also comparing the wall build with industrial brick and wall with handmade brick, has similar values for immediate occupancy (IO) and little bit less for life safety (LS).

Due to NTE-030 maximum drift limit (1/200) for reparability of the structure only meet in the case of wall with industrial bricks, two drift threshold are proposed, for wall with handmade bricks $1 / 300$ and for wall with horizontal hollow tubular wall 1/590. These values represent a real limit for each of these wall likely used in non-engineering housing. 


\section{ACKNOWLEDGEMENT}

Authors must include the acknowledgment to the Program PP-068 of the Ministry of Economy and Finance for the support of test presented on this paper. Also, our gratitude to the Ministry of Construction, Housing and Sanitation - SENCICO, to give us the chance to complement our data base with their results. Also to the technical staff of CISMID Structural Laboratory to work hard in the perform of the wall experiments during evening and weekends, our appreciation for this detail. Finally, our gratitude to our students and assistant researchers of the CISMID, to support us during the experiments.

\section{REFERENCES}

[1] Cardenas L, Roy R, Estacio L and Zavala C 2014 Implementation of Database of Masonry Walls Test - Review of Existing Test Data in Peru. Journal of Disaster Research9(6)

[2] CISMID 2015 Comparison of Behavior of Non-Engineering Masonry Walls under Lateral Cyclic Loading without and with Retrofitting. Program 0068 - Reduction of Vulnerability and Assistant of emergencies by Disasters. Lima-Peru. 2015(In Spanish)

[3] CISMID 2017 "Tests of full-scale walls and elaboration of corresponding fragility curves oriented to the development of knowledge about seismic behavior of nonengineered masonry walls and to enable the estimation of losses for earthquake scenario", Report commissioned by SENCICO

[4] CISMID 2015 Experimental Study of Mechanical Properties of Tubular Units without and with Retrofitting. Program 0068 Reduction of Vulnerability and Assistant of Emergencies by Disasters. Lima-Peru(In Spanish)

[5] Diaz M, Zavala C, Gallardo J, Lavado L 2017 “Experimental study of non-engineered confined masonry walls retrofitted with wire mesh and cement-sand mortar", 16th World Conference on Earthquake Engineering, Chile
[6] Diaz M 2019 Report on statistical analysis and target study Area in Lima Metropolitan and Callao. Project FONDECYT-CISMID-FICUNI Development a digital tool for feasibility of confined masonry dwelling retrofitting in multi seismic scenarios based on assessment of vulnerability and risk

[7] Lavado L, Taira J and Gallardo J 2014Current State of Masonry Properties Material on Emerging Zones in Lima City. Journal of Disaster Research,9(6)

[8] Salinas R and Lazares F 2008 Seismic Performance of Confined Masonry Buildings with Tubular Bricks in Developing Areas. Proceedings of 14th World Conference on Earthquake Engineering. China

[9] SENCICO 2006 Norma E-070 Masonry. Ministry of Construction, Housing and Sanitation. Peru

[10] Sugano S, Saito T, Zavala C and Cardenas L 2014 Strength and Deformation of Confined Brick Masonry Walls Subjected to Lateral Forces - Review of Existing Test Data in Japan and Peru. Journal of Disaster Research,9(6)

[11] Pulido N, Tavera H, Perfettini H, Chlieh M, Aguilar Z, Aoi S, Nakai S, and Yamazaki F 2011 Estimation of Slip Scenarios for Megathrust Earthquakes: A Case Study for Peru, in Effects of Surface Geology on Seismic Motion, pp 1-6

[12] Saito 2019 Technical Manual Version 6.1 of Structural Earthquake Response Analysis (STERA)

[13] Zavala C and Kaminosono T, et al 2003 "Construction Monitoring and Improvement Techniques for Masonry Housing," CISMIDIDI Repor

[14] Zavala C, Lavado L, Taira J, Cardenas L and Diaz M 2014 Comparison of Behaviors of Non-Engineered Masonry Tubular Block Walls and Solid Engineered Walls. Journal of Disaster Research9(6)

[15] CISMID 2013 Report of Project NGO Save The children- CISMID Support for Reduction of Risk in Lima Neighborhoods (ARRIBA), Lima-Peru

[16] Zavala C, Estrada M and Taira Y 2012 Loss Estimation on Lima City Using a Retrofitting Cost Estimation Tool, Proceedings of the 9th International Conference on Urban Earthquake Engineering/ 4th Asia Conference on Earthquake Engineering, Tokyo Institute of Technology, Tokyo

[17] Zavala C, Honma C Gibu P Gallardo J and Huaco G 2004 Full Scale On Line Test On Two Story Masonry Building Using Handmade Bricks, Proceedings of 13th World Conference on Earthquake Engineering Vancouver, B.C., Canada, Paper No. 2885 